\title{
Estudo psicométrico da Escala de Interesses por Áreas da Psicologia (EIAPsi)
}

\author{
Rodolfo Augusto Matteo Ambiel ${ }^{1}$ \\ Gustavo Henrique Martins ${ }^{2}$ \\ ${ }^{I}$ Universidade São Francisco, SP, Brasil \\ http://orcid.org/0000-0002-3921-8547 \\ ${ }^{2}$ Universidade São Francisco, SP, Brasil \\ http://orcid.org/0000-0002-5125-2553
}

\begin{abstract}
Resumo
Os estudantes de Psicologia devem realizar escolhas profissionais durante o curso, podendo vivenciar um período angustiante. O objetivo deste artigo foi buscar evidências de validade e precisão para a Escala de Interesses por Áreas da Psicologia (EIAPsi) e verificar as diferenças do sexo e período do curso nas médias dos interesses. Participaram 980 estudantes de Psicologia que responderam a EIAPsi. Os resultados indicaram 11 fatores como melhor estrutura para EIAPsi, os quais apresentaram bons índices de precisão. Notou-se que as mulheres pontuaram mais que os homens nas áreas Saúde e Jurídica, sendo o oposto observado na área Docência e Pesquisa. Os estudantes do fim do curso apresentaram um perfil de interesses mais discriminado que os demais. A partir dos resultados foi possível identificar a viabilidade da utilização da EIAPsi por estudantes de Psicologia no contexto brasileiro.
\end{abstract}

Palavras-chave: orientação vocacional, interesses profissionais, ensino superior, avaliação psicológica, testes psicológicos.

\section{Psychometric Study Of The Scale Of Interests By Areas Of Psychology - EIAPsi}

\begin{abstract}
Students of Psychology must make professional choices during the course and may experience a harrowing period. The objective of this article was to search for evidence of validity and precision for the Psychology Interests Range by Areas of Psychology (EIAPsi) and to verify the differences of gender and period of the course in the averages of interests. Participated 980 psychology students who answered an EIAPsi. The results presented are 11 factors as best structure for EIAPsi, which are good indexes of precision. She noted that women scored more than men in the areas of Health and Legal, and the body was observed in the area of Teaching and Research. End-of-course students have a more discriminated interests profile than others. From the obtained results, the viability of the use of EIAPsi by students of Psychology in the Brazilian context can be used.
\end{abstract}

Keywords: vocational guidance, professional interests, higher education, psychological assessment, psychological tests.

\section{Estudio Psicométrico De La Escala De Intereses Por Áreas De La Psicología - EIAPsi}

\section{Resumen}

Los estudiantes de Psicología deben realizar elecciones profesionales durante el curso, pudiendo experimentar un período angustiante. El objetivo de este artículo fue buscar evidencias de validez y precisión para la Escala de Intereses por Áreas de la Psicología (EIAPsi) 
y verificar las diferencias del sexo y el período del curso en las medias de los intereses. Participaron 980 estudiantes de Psicología que respondieron un EIAPsi. Los resultados presentados son 11 factores como mejor estructura para EIAPsi, los cuales son buenos índices de precisión. Se observó que las mujeres puntualizó más que los hombres en las áreas de Salud y Jurídica, siendo el cuerpo observado en el área de Docencia e Investigación. Los estudiantes del final del curso presentan un perfil de intereses más discriminados que los demás A partir de dos resultados, es posible identificar la viabilidad del uso del EIAP por estudiantes de psicología, no el contexto brasileño.

Palabras clave: orientación vocacional, intereses profesionales, enseñanza superior, evaluación psicológica, pruebas psicológicas.

Os estudantes de Psicologia, assim como ocorre em outras áreas do conhecimento, devem realizar escolhas profissionais durante a graduação, sendo uma delas a opção pelas áreas de estágio (Souza \& Souza, 2012). Durante esse período de decisão, os estudantes podem não conseguir identificar facilmente quais áreas de atuação mais lhes interessam, procurando assim formas de auxílio para essa tarefa. Instrumentos que avaliem os interesses profissionais dos estudantes a respeito especificamente dos campos de atuação da profissão de Psicologia, poderiam ser ferramentas úteis para a etapa de autoconhecimento realizada por profissionais e instituições que se propõem oferecer tal ajuda (Andrade, Pissaia, Silva, \& Oliveira, 2016; Bueno, Lemos, \& Tomé, 2004; Campos, Catão, \& Fujii, 1999). Sendo assim, pretende-se com este artigo testar as evidências de validade e estimativas de precisão da Escala de Interesses por Áreas da Psicologia (EIAPsi).

Estudos têm indicado que as pessoas escolhem o curso de Psicologia por observar nessa profissão a possibilidade de ajudarem pessoas (Daltro \& Pondé, 2017; Hernández-Franco, Baena, Prieto-Ursúa, \& Toro, 2018; Magalhães, Straliotto, Keller, \& Gomes, 2001). Contudo, pouco se sabe sobre como ocorrem as escolhas durante a graduação de Psicologia a respeito das diversas áreas de atuação da profissão. Souza e Souza (2012) apontaram em seu estudo que a experiência prática nos estágios realizados durante o curso foram a principal fonte de influência para a escolha das áreas de atuação. Portanto, mecanismos de auxílio ao estudante de Psicologia devem ser pensados e promovidos pelas instituições de ensino, para que o processo de escolha profissional não seja algo tão angustiante e sofrido (Andrade et al., 2016). Nesse sentido, instrumentos que avaliam os interesses profissionais podem ser ferramentas úteis para a promoção do autoconhecimento do estudante, contribuindo assim com a sua escolha (Andrade et al., 2016; Bueno et al., 2004; Campos et al., 1999).

Os interesses profissionais podem ser definidos como padrões de gosto, aversão ou indiferença frente a atividades e ocupações relevantes para a carreira (Lent, Brown, \& Hackett, 1994). Adicionalmente, Round e $\mathrm{Su}$ (2014) definem os interesses como traços que representam preferências por atividades, contextos em que as atividades ocorrem e também pelos resultados associados às atividades preferidas. Segundo os autores, essa preferência é motivadora de comportamentos orientados por objetivos, direcionando o indivíduo para certos ambientes. Os interesses profissionais aparecerem evidenciados na literatura como sendo relativamente estáveis ao longo do tempo (Low \& Rounds, 2007; Schultz, Connolly, Garrison, Leveille, \& Jackson, 2017) e com homens preferindo atividades que envolvam coisas, e mulheres atividades que envolvam pessoas (Hoff, Briley, Wee, \& Rounds, 2018; Su, Rounds, \& Armstrong, 2009).

Além das pontuações tradicionais fornecidas pelos inventários de interesses, alguns autores enfatizam a importância de se utilizar também os conceitos secundários de interesses de forma complementar para que haja assim uma melhor compreensão do desenvolvimento de carreira do indivíduo (Bullock \& Reardon, 2008; Holland, 1997; Im, 2011; Jaensch, Hirschi, \& Spurk, 2016). Dois desses conceitos secundários são a elevação dos interesses e a nitidez ou diferenciação do perfil dos interesses. A elevação consiste em um nível geral das pontuações de interesses (Fuller, Holland, \& Johnston, 1999). A nitidez corresponde ao grau em que as características de interesses são claramente distintas, ou seja, maior nitidez 
representa maior clareza no processo de tomada de decisão (Holland, 1997). Um estudo revelou que a elevação prediz positivamente autoeficácia ocupacional e engajamento na carreira, e a nitidez prediz positivamente a decisão e o engajamento na carreira (Jaensch et al., 2016).

A respeito da avaliação dos interesses, há relatos na literatura sobre medidas de interesses profissionais específicos para o contexto da Psicologia (Campos et al., 1999; Ferreira, Rodrigues, \& Ferreira, 2015; Rabelo, Pilati, \& Porto, 2016; Rodrigues, Ferreira, \& BártoloRibeiro, 2013). Em Portugal, foi desenvolvida a Escala de Interesses por Psicologia, composta por 21 itens que representam três áreas da Psicologia, sendo essas: Clínica, Educacional e Organizacional. Os estudos demonstraram boas propriedades psicométricas para o instrumento, com coeficientes alfa variando de 0,86 (Educacional) a 0,96 (Clínica). Além disso, foram obtidas correlações com os tipos de interesses do RIASEC, sendo as áreas Clínica e Educacional correlacionadas positivamente com o tipo Social e a área Organizacional correlacionada positivamente com o tipo Empreendedor (Ferreira et al., 2015; Rodrigues et al., 2013).

Campos et al. (1999) testaram a viabilidade do Inventários Cientista Prático no contexto brasileiro, sendo esse um instrumento desenvolvido originalmente nos Estados Unidos. Os autores traduziram o instrumento e aplicaram em uma amostra composta por 46 alunos do quarto ano de Psicologia. O instrumento é composto por 42 itens, divididos em sete possibilidades de áreas de atuação, sendo essas Atividades Terapêuticas, Clínica, Teste e Interpretação, Pesquisa, Estatística, ProfessorEditor-Supervisor e Ideias Acadêmicas. Foram analisadas as frequências das respostas dos participantes em cada área de atuação avaliada pelo instrumento, sendo constatada a maior preferência dos estudantes pelas atividades da área Clínica em oposição às atividades relacionadas à pesquisa ou estatística. Por fim, os autores discutem que o instrumento parece medir apenas duas áreas, sendo estas Clínica e Pesquisa, sugerindo o desenvolvimento de novas medidas de orientação profissional baseadas na realidade da Psicologia no Brasil.

No contexto nacional também foram desenvolvidas duas medidas de atitudes frente às áreas Clínica $\mathrm{e}$ Organizacional, uma implícita e outra explícita. Por meio dos estudos conduzidos com 141 estudantes de Psicologia, foi identificado que a atitude explicita foi preditora positiva da atitude implícita, além de favoráveis estimativas de precisão para as medidas. É discutida pelos autores a importância da utilização de medidas implícitas e explicitas para que aumente a capacidade diagnóstica e preditiva dos construtos (Rabelo et al., 2016).

Como descrito anteriormente, alguns estudos visaram construir e buscar evidências de validade para instrumentos que avaliam os interesses profissionais específicos para o contexto da Psicologia, podendo assim contribuir com evidências de como são expressos os interesses dos estudantes a respeito de algumas áreas específicas da profissão de psicólogo(a). Entretanto, os instrumentos descritos anteriormente apresentaram como limitações a quantidade de áreas de atuação avaliadas, o baixo número amostral e a falta de representatividade da realidade da Psicologia no Brasil. Tendo em vista que no Brasil há uma grande diversidade de áreas de atuação dentro da Psicologia, um instrumento que seja construído para representar a realidade brasileira, com estudos psicométricos sólidos e que avalie grande parte das áreas de atuação da profissão, torna-se mais informativo e, portanto, útil em processos de intervenções.

Nesse sentido, os autores do presente artigo construíram a Escala de Interesses por Áreas da Psicologia (EIAPsi). Os itens do instrumento foram construídos em uma disciplina de graduação em Psicologia, com base inicialmente na Resolução CFP N.o 013/2007, que consolida as resoluções relativas ao título profissional de especialista em Psicologia, e em outros levantamentos realizados junto a instituições de Ensino Superior e institutos de pós-graduação. Informações mais detalhadas sobre o processo de construção podem ser verificadas em Ambiel e Martins (no prelo). Em outros estudos anteriores foram 
constatadas evidências de validade baseadas no conteúdo (Martins, Hernández, \& Ambiel, 2014) e na relação com outras variáveis (Ambiel \& Martins, 2016a). A EIAPsi também foi adaptada para o contexto português, sendo constatadas evidências de validade baseadas na estrutura interna e estimativas de precisão satisfatórias para o instrumento, além de ter sido também explorada a relação entre interesses por áreas da Psicologia e de personalidade no modelo Big Five (Ambiel et al., no prelo).

Contudo, outras evidências de validade e estimativas de precisão ainda se fazem necessárias. Sendo assim, o objetivo deste artigo foi buscar evidências de validade baseadas na estrutura interna e estimativas de precisão para a EIAPsi. Além disso, de forma exploratória, buscou-se verificar as diferenças nas médias dos interesses por áreas da Psicologia, da elevação do perfil dos interesses e da nitidez dos interesses dos participantes divididos pelo sexo e período do curso.

\section{Método}

\section{Participantes}

A amostra foi composta por 980 estudantes de Psicologia, sendo 791 do sexo feminino (80,7\%) e 170 $(17,3 \%)$ do sexo masculino, com idades variando de 18 a $64 \operatorname{anos}(M=25,17 ; D P=7,70)$. No total, 21 estados brasileiros foram representados pela amostra deste estudo, com 488 participantes residentes da região Sudeste (49,8\%), 345 da região Sul (35,2\%), 84 da região Nordeste (8,6\%), 43 da região Norte $(4,4 \%)$ e 17 da região Centro-Oeste (1,7\%). Grande parte dos participantes cursava Psicologia em universidades particulares $(n$ $=875 ; 89,3 \%$ ). Todos os cinco anos do curso foram representados, sendo os participantes distribuídos da seguinte forma: $1 .^{\circ}$ ano $(n=57 ; 5,8 \%) ; 2 .^{\circ}$ ano $(n=237$; $24,2 \%) ; 3^{\circ}$ ano $(n=318 ; 32,4 \%) ; 4 .^{\circ}$ ano $(n=181 ; 18,5 \%)$; e $5^{\circ}$ ano $(n=168 ; 17,1 \%)$. Os participantes responderam à pesquisa de forma presencial $(n=388 ; 39,6 \%) \mathrm{e}$ online $(n=592 ; 60,4 \%)$. Não foram encontrados efeitos substanciais nas respostas dos participantes em relação aos métodos de coleta de dados $(d<0,19)$.

\section{Instrumentos}

Questionário sociodemográfico. Foi desenvolvido para este projeto e buscou identificar a amostra em relação ao sexo, idade, estado de residência, tipo da universidade e ano do curso.

Escala de Interesses por Áreas da Psicologia EIAPsi (Ambiel \& Martins, 2016b). Avalia os interesses profissionais de estudantes de Psicologia, acerca das diferentes áreas de atuação ofertadas pela profissão. A escala é composta por 90 itens, os quais são divididos em 11 áreas: Clínica, Saúde, Educacional, Organizacional, Social, Avaliação Psicológica, Docência e Pesquisa, Trânsito, Esporte, Jurídica e Neuropsicologia. A chave de resposta é dada em uma escala Likert de cinco pontos que varia de " 1 - Detesto/detestaria exercer essa atividade" a " 5 - Adoro/adoraria exercer essa atividade". A busca pelas propriedades psicométricas para a EIAPsi é o foco deste artigo, apesar de já haver algumas evidências iniciais, conforme citado anteriormente (Ambiel \& Martins, 2016a; Ambiel \& Martins, no prelo; Martins et al., 2014). $\mathrm{O}$ instrumento na íntegra pode ser verificado no Anexo.

\section{Procedimentos de coleta de dados}

A coleta de dados ocorreu de forma presencial no formato lápis e papel nas instituições que aceitam participar da pesquisa. Foram também disponibilizados convites para a pesquisa a potenciais participantes por e-mail e redes sociais, a fim de que os interessados participassem da coleta online por meio do aplicativo Google Formulários. Uma parte dos estudantes $(n=60)$ participou da pesquisa de forma online em duas oportunidades, sendo a segunda participação ocorrida um mês após o estudante ter respondido a pesquisa pela primeira vez. Esses estudantes não participaram de nenhuma intervenção de orientação profissional durante esse período. 


\section{Procedimentos de análise de dados}

Os dados foram analisados por meio dos softwares

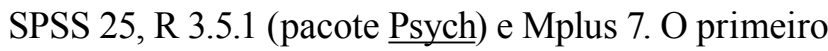
passo consistiu em analisar as estatísticas descritivas da amostra e do instrumento. Para verificar a adequação fatorial dos dados foi adotada a estatística do KaiserMeyer-Olkin (KMO). Na sequência foi verificado qual o número ideal de fatores a serem extraídos do conjunto de dados, por meio dos métodos de retenção fatorial Very Simple Structure(VSS), Minimum Average Partial (MAP) e Análise Paralela. Para se verificar a forma como os itens se agrupavam foi realizada uma Exploratory Structural Equation Modeling (ESEM), com estimador WLSMV e rotação Geomin. A verificação do ajuste do modelo foi feita a partir da razão qui-quadrado por graus de liberdade $\left(\mathrm{X}^{2} / \mathrm{gl}<3\right)$, Confirmatory Fit Index (CFI > 0,95), Tucker-Lewis Index (TLI > 0,95), Root Mean Square Error of Approximation (RMSEA $<0,05$ ) e Weighted Root Mean Square Residual (WRMR $<1$ ) (Hu \& Bentler, 1999). Para manutenção dos itens foi utilizado o critério de cargas fatoriais maiores que 0,30 . A precisão por consistência interna foi verificada por meio do coeficiente alfa de Cronbach e a precisão teste-reteste foi verificada por meio da correlação de Pearson entre os escores obtidos nos dois momentos de aplicação. Os índices de precisões (alfa e teste-reteste) maiores que 0,70 são considerados satisfatórios (Nunnally, 1978).

Para a obtenção do valor da elevação dos interesses foi calculada a média geral de cada participante considerando todos os fatores da EIAPsi (Fuller et al., 1999). Por sua vez, a nitidez do perfil dos interesses foi calculada mediante o desvio padrão que cada participante obteve em relação à média de todos os fatores da EIAPsi, permitindo assim verificar as distâncias entre os fatores (Holland, 1997; Noronha \& Ambiel, 2015). Por fim, as comparações de grupo em relação ao sexo e ao ano de curso dos participantes foi realizada por meio do Teste $t$ de Student e Análise de Variância (ANOVA), sendo que no caso do teste $\mathrm{T}$ foram também verificados os tamanhos de efeito ( $d$ de Cohen) das diferenças, e no caso da ANOVA, foi utilizada a prova post hoc de Tukey. Os coeficientes de correlação $(r)$ e tamanhos de efeito $(d)$ foram interpretados seguindo Cohen (1992), o qual aponta que $r>0,10$ são fracas, $r>0,30$ são moderadas e $r>0,50$ são correlações fortes, ao passo que $d>0,20$ são fracos, $d>0,50$ são moderados e $d>$ 0,80 são tamanhos de efeito fortes.

\section{Procedimentos éticos}

Após o aceite das instituições de ensino superior em participar da pesquisa, o projeto foi submetido e aprovado pelo Comitê de Ética em Pesquisa da Universidade São Francisco (CAEE: 34976414.4.0000.5514). Os participantes somente tiveram acesso ao restante da pesquisa mediante concordância com o Termo de Consentimento Livre e Esclarecido (TCLE).

\section{Resultados}

Ao verificar o valor do $\mathrm{KMO}=0,94$, foi visto que esse sugere que os dados estão adequados para serem submetidos à análise fatorial. Em seguida foram utilizados três métodos de retenção fatorial, sendo que VSS indicou três fatores, MAP indicou 14 fatores e Análise Paralela indicou 12 fatores. Contudo, como a hipótese teórica era que 11 áreas da Psicologia fossem representadas pelos 90 itens, foi testada a estrutura fatorial formada por 11 fatores por meio da ESEM. A seguir, na Tabela 1, estão descritas as cargas fatoriais, comunalidades, índices de precisão, percentis e a matriz de correlação entre as variáveis latentes, referentes à ESEM realizada para a EIAPsi. 
Tabela 1. ESEM da EIAPsi, descritiva e correlação dos fatores.

\begin{tabular}{|c|c|c|c|c|c|c|c|c|c|c|c|c|}
\hline Itens & Jur & Doc & Clí & Org & Saú & Edu & Esp & $\mathbf{A P}$ & Soc & Neu & Trâ & $\mathbf{h}^{2}$ \\
\hline item 1 & $-0,03$ & 0,86 & $-0,10$ & $-0,07$ & 0,15 & $-0,05$ & 0,02 & 0,21 & 0,00 & $-0,21$ & $-0,27$ & 0,84 \\
\hline item 2 & 0,11 & 0,02 & 0,01 & 0,05 & 0,00 & 0,03 & 0,01 & 0,69 & $-0,19$ & $-0,02$ & 0,06 & 0,56 \\
\hline item 3 & 0,86 & $-0,01$ & 0,03 & $-0,03$ & $-0,04$ & $-0,03$ & $-0,05$ & $-0,04$ & $-0,03$ & 0,07 & 0,07 & 0,74 \\
\hline item 4 & 0,11 & 0,04 & $-0,04$ & 0,05 & 0,01 & $-0,04$ & $-0,02$ & 0,05 & 0,02 & 0,66 & $-0,09$ & 0,49 \\
\hline item 5 & 0,08 & 0,07 & 0,13 & 0,11 & $-0,01$ & $-0,01$ & $-0,06$ & $-0,08$ & 0,63 & 0,07 & $-0,14$ & 0,46 \\
\hline item 6 & 0,82 & 0,00 & 0,08 & $-0,04$ & 0,00 & $-0,01$ & $-0,09$ & 0,09 & $-0,08$ & 0,13 & 0,07 & 0,76 \\
\hline item 7 & 0,00 & 0,71 & $-0,04$ & $-0,01$ & 0,00 & 0,00 & 0,08 & 0,06 & 0,15 & $-0,01$ & $-0,12$ & 0,59 \\
\hline item 8 & $-0,08$ & $-0,07$ & $\mathbf{0 , 8 1}$ & $-0,07$ & 0,08 & 0,01 & 0,07 & 0,01 & $-0,03$ & $-0,07$ & $-0,02$ & 0,68 \\
\hline item 9 & 0,01 & 0,07 & 0,09 & $-0,01$ & 0,04 & $\mathbf{0 , 8 2}$ & 0,03 & 0,01 & $-0,08$ & $-0,01$ & $-0,08$ & 0,68 \\
\hline item 10 & 0,76 & 0,09 & $-0,05$ & 0,01 & $-0,02$ & 0,01 & 0,06 & $-0,11$ & 0,10 & 0,08 & 0,05 & 0,67 \\
\hline item 11 & 0,05 & 0,04 & 0,08 & 0,02 & $\mathbf{0 , 8 2}$ & 0,01 & 0,02 & $-0,06$ & $-0,05$ & $-0,04$ & $-0,01$ & 0,70 \\
\hline item 12 & $-0,01$ & 0,02 & $-0,16$ & 0,02 & 0,17 & 0,21 & 0,11 & 0,15 & $-0,05$ & 0,55 & $-0,06$ & 0,54 \\
\hline item 13 & 0,02 & $-0,08$ & $-0,01$ & 0,10 & 0,21 & 0,14 & $-0,06$ & $-0,01$ & 0,58 & $-0,09$ & $-0,02$ & 0,54 \\
\hline item 14 & $-0,02$ & 0,90 & $-0,09$ & $-0,03$ & 0,16 & $-0,04$ & 0,02 & 0,22 & 0,03 & $-0,20$ & $-0,25$ & 0,92 \\
\hline item 15 & $\mathbf{0 , 8 2}$ & 0,02 & $-0,06$ & $-0,01$ & 0,19 & $-0,04$ & 0,00 & 0,09 & $-0,02$ & $-0,15$ & $-0,06$ & 0,73 \\
\hline item 16 & 0,15 & $-0,04$ & 0,26 & $-0,01$ & 0,11 & 0,03 & $-0,08$ & 0,60 & $-0,10$ & 0,05 & $-0,05$ & 0,54 \\
\hline item 17 & 0,07 & $-0,06$ & 0,02 & 0,83 & 0,06 & 0,05 & $-0,01$ & $-0,04$ & 0,02 & $-0,02$ & $-0,08$ & 0,68 \\
\hline item 18 & 0,06 & $-0,02$ & 0,00 & 0,08 & 0,39 & 0,04 & $-0,02$ & 0,07 & $-0,07$ & 0,59 & $-0,06$ & 0,61 \\
\hline item 19 & 0,66 & $-0,05$ & 0,00 & 0,07 & 0,30 & 0,04 & 0,00 & 0,02 & 0,19 & $-0,20$ & $-0,06$ & 0,70 \\
\hline item 20 & 0,04 & $-0,07$ & 0,00 & 0,07 & 0,05 & 0,63 & 0,08 & 0,02 & 0,28 & $-0,10$ & $-0,06$ & 0,70 \\
\hline item 21 & 0,17 & 0,09 & 0,03 & 0,03 & 0,01 & 0,08 & 0,02 & 0,57 & $-0,01$ & 0,04 & $-0,03$ & 0,49 \\
\hline item 22 & 0,04 & 0,23 & $-0,11$ & 0,02 & $-0,02$ & 0,13 & 0,07 & 0,03 & 0,68 & $-0,10$ & $-0,04$ & 0,65 \\
\hline item 23 & $-0,01$ & $-0,06$ & $-0,04$ & $-0,01$ & 0,04 & 0,11 & 0,65 & $-0,04$ & 0,25 & 0,01 & $-0,01$ & 0,62 \\
\hline item 24 & $-0,02$ & $-0,06$ & 0,02 & 0,00 & $-0,01$ & 0,85 & 0,12 & 0,01 & 0,04 & $-0,05$ & $-0,07$ & 0,81 \\
\hline item 25 & 0,04 & $-0,05$ & 0,44 & $-0,04$ & 0,37 & 0,15 & 0,05 & 0,07 & 0,12 & $-0,03$ & $-0,07$ & 0,54 \\
\hline item 26 & 0,75 & 0,01 & $-0,10$ & 0,00 & 0,19 & 0,05 & 0,07 & 0,00 & 0,13 & $-0,15$ & $-0,06$ & 0,71 \\
\hline item 27 & 0,02 & 0,04 & 0,00 & 0,04 & 0,90 & $-0,01$ & 0,03 & $-0,03$ & $-0,12$ & 0,01 & 0,02 & 0,78 \\
\hline item 28 & $-0,08$ & 0,67 & 0,03 & $-0,10$ & 0,02 & $-0,08$ & 0,00 & 0,12 & 0,15 & 0,02 & $-0,08$ & 0,55 \\
\hline item 29 & $-0,01$ & 0,14 & $-0,08$ & 0,75 & 0,03 & 0,01 & 0,04 & 0,04 & 0,04 & 0,06 & $-0,01$ & 0,65 \\
\hline item 30 & 0,00 & 0,24 & 0,52 & 0,10 & 0,11 & 0,01 & 0,02 & $-0,02$ & $-0,13$ & 0,03 & $-0,02$ & 0,40 \\
\hline item 31 & 0,06 & 0,01 & 0,20 & 0,05 & 0,63 & 0,11 & 0,04 & $-0,02$ & $-0,05$ & 0,06 & 0,03 & 0,59 \\
\hline item 32 & $-0,04$ & 0,00 & 0,03 & $\mathbf{0 , 8 2}$ & 0,04 & 0,09 & 0,07 & $-0,06$ & 0,03 & $-0,03$ & $-0,01$ & 0,76 \\
\hline item 33 & $-0,05$ & $-0,01$ & 0,03 & 0,03 & 0,00 & 0,40 & 0,52 & $-0,05$ & 0,00 & 0,02 & 0,03 & 0,59 \\
\hline item 34 & 0,07 & 0,61 & 0,20 & 0,08 & 0,01 & 0,32 & $-0,04$ & $-0,12$ & $-0,07$ & $-0,05$ & 0,06 & 0,52 \\
\hline item 35 & 0,00 & 0,11 & $-0,02$ & 0,14 & 0,03 & 0,01 & 0,38 & 0,02 & 0,08 & $-0,03$ & 0,56 & 0,68 \\
\hline item 36 & $-0,03$ & $-0,06$ & 0,74 & 0,01 & 0,09 & 0,03 & 0,10 & 0,04 & 0,12 & $-0,13$ & 0,02 & 0,65 \\
\hline item 37 & 0,63 & $-0,07$ & 0,15 & 0,03 & $-0,01$ & $-0,05$ & 0,06 & $-0,01$ & 0,07 & 0,00 & 0,13 & 0,52 \\
\hline item 38 & 0,14 & $-0,05$ & 0,08 & $-0,07$ & 0,05 & 0,06 & 0,09 & 0,01 & 0,76 & $-0,05$ & 0,03 & 0,74 \\
\hline item 39 & 0,06 & $-0,01$ & 0,02 & $-0,03$ & $-0,07$ & 0,07 & 0,85 & $-0,05$ & 0,08 & 0,04 & 0,00 & 0,79 \\
\hline item 40 & $-0,02$ & 0,80 & $-0,03$ & $-0,02$ & $-0,05$ & 0,01 & 0,10 & 0,05 & 0,14 & 0,01 & $-0,06$ & 0,74 \\
\hline item 41 & 0,05 & $-0,05$ & $-0,06$ & 0,86 & 0,02 & 0,00 & $-0,02$ & 0,06 & $-0,13$ & 0,03 & 0,02 & 0,77 \\
\hline
\end{tabular}




\begin{tabular}{|c|c|c|c|c|c|c|c|c|c|c|c|c|}
\hline Itens & Jur & Doc & Clí & Org & Saú & Edu & Esp & AP & Soc & Neu & Trâ & $\mathbf{h}^{2}$ \\
\hline item 42 & $-0,02$ & 0,10 & $-0,03$ & 0,10 & $-0,05$ & $\mathbf{0 , 8 0}$ & 0,02 & $-0,02$ & 0,06 & 0,03 & $-0,01$ & 0,76 \\
\hline item 43 & 0,03 & 0,02 & 0,05 & 0,02 & $-0,04$ & 0,03 & 0,95 & $-0,06$ & $-0,07$ & 0,03 & $-0,03$ & 0,90 \\
\hline item 44 & 0,03 & 0,03 & 0,63 & $-0,06$ & 0,06 & $-0,06$ & 0,03 & 0,13 & 0,12 & 0,06 & $-0,08$ & 0,51 \\
\hline item 45 & 0,01 & 0,06 & 0,11 & 0,66 & $-0,07$ & 0,05 & 0,13 & 0,08 & $-0,06$ & 0,00 & $-0,03$ & 0,60 \\
\hline item 46 & 0,00 & 0,04 & 0,03 & 0,05 & $-0,07$ & 0,48 & 0,06 & 0,48 & $-0,09$ & 0,06 & 0,08 & 0,64 \\
\hline item 47 & 0,00 & $-0,10$ & $-0,08$ & 0,34 & 0,07 & 0,07 & 0,01 & 0,11 & 0,52 & $-0,06$ & 0,04 & 0,55 \\
\hline item 48 & 0,00 & 0,69 & 0,25 & 0,04 & $-0,11$ & 0,26 & $-0,08$ & $-0,20$ & $-0,08$ & 0,00 & 0,04 & 0,59 \\
\hline item 49 & 0,06 & 0,22 & 0,25 & 0,05 & $-0,06$ & 0,11 & $-0,06$ & 0,48 & $-0,09$ & $-0,02$ & 0,05 & 0,47 \\
\hline item 50 & 0,11 & 0,00 & 0,23 & $-0,04$ & 0,58 & $-0,02$ & 0,02 & 0,01 & 0,06 & 0,06 & $-0,02$ & 0,53 \\
\hline item 51 & 0,08 & 0,01 & 0,00 & 0,01 & $-0,03$ & 0,03 & 0,79 & 0,12 & $-0,14$ & 0,03 & 0,05 & 0,70 \\
\hline item 52 & $-0,02$ & $-0,02$ & 0,01 & $-0,02$ & 0,26 & 0,03 & 0,08 & 0,00 & 0,04 & 0,81 & $-0,02$ & 0,82 \\
\hline item 53 & 0,01 & 0,05 & $-0,04$ & 0,05 & 0,15 & 0,00 & 0,39 & 0,03 & 0,08 & 0,09 & 0,51 & 0,63 \\
\hline item 54 & 0,03 & 0,93 & 0,12 & 0,02 & $-0,02$ & 0,15 & $-0,03$ & $-0,19$ & $-0,09$ & 0,01 & 0,09 & 0,86 \\
\hline item 55 & 0,01 & 0,08 & $-0,05$ & 0,90 & $-0,01$ & 0,01 & $-0,02$ & 0,00 & 0,03 & 0,03 & $-0,02$ & 0,81 \\
\hline item 56 & $-0,10$ & 0,09 & 0,62 & 0,02 & 0,05 & $-0,12$ & $-0,03$ & 0,07 & 0,05 & $-0,03$ & $-0,07$ & 0,42 \\
\hline item 57 & 0,50 & 0,33 & 0,01 & $-0,02$ & $-0,08$ & $-0,07$ & 0,08 & 0,01 & 0,12 & 0,09 & 0,11 & 0,49 \\
\hline item 58 & 0,08 & 0,10 & 0,18 & 0,02 & $-0,13$ & 0,01 & $-0,05$ & 0,61 & 0,05 & 0,12 & 0,04 & 0,60 \\
\hline item 59 & 0,02 & 0,02 & $-0,04$ & $-0,05$ & 0,09 & $-0,03$ & 0,07 & 0,22 & 0,02 & 0,78 & $-0,02$ & 0,84 \\
\hline item 60 & $-0,01$ & 0,05 & $-0,05$ & $-0,06$ & 0,28 & 0,54 & 0,00 & 0,14 & 0,13 & 0,11 & 0,00 & 0,57 \\
\hline item 61 & $-0,04$ & 0,38 & $-0,15$ & 0,08 & 0,02 & 0,00 & 0,11 & 0,27 & 0,01 & 0,12 & 0,03 & 0,39 \\
\hline item 62 & $-0,03$ & 0,03 & 0,02 & $-0,05$ & 0,42 & 0,04 & $-0,02$ & 0,02 & 0,47 & $-0,02$ & 0,21 & 0,57 \\
\hline item 63 & $-0,04$ & $-0,05$ & $-0,09$ & $-0,15$ & 0,29 & 0,63 & $-0,08$ & 0,12 & 0,08 & 0,11 & 0,06 & 0,58 \\
\hline item 64 & 0,03 & $-0,05$ & $-0,05$ & $\mathbf{0 , 8 1}$ & 0,08 & $-0,01$ & 0,02 & 0,08 & $-0,12$ & $-0,05$ & 0,09 & 0,74 \\
\hline item 65 & 0,01 & 0,00 & 0,03 & 0,07 & 0,01 & $-0,04$ & 0,89 & 0,02 & $-0,01$ & $-0,01$ & $-0,03$ & 0,84 \\
\hline item 66 & $-0,02$ & 0,08 & 0,12 & 0,16 & $-0,06$ & 0,02 & 0,08 & 0,54 & 0,07 & 0,07 & 0,07 & 0,56 \\
\hline item 67 & $-0,08$ & 0,06 & $\mathbf{0 , 5 7}$ & 0,00 & 0,01 & 0,00 & 0,09 & 0,18 & 0,12 & 0,11 & 0,03 & 0,52 \\
\hline item 68 & 0,12 & $-0,03$ & $-0,02$ & 0,01 & 0,02 & $-0,02$ & 0,38 & 0,18 & $-0,05$ & $-0,04$ & 0,67 & 0,78 \\
\hline item 69 & $-0,01$ & $-0,02$ & 0,13 & $-0,02$ & 0,04 & 0,01 & 0,04 & 0,28 & $-0,02$ & 0,63 & 0,09 & 0,70 \\
\hline item 70 & 0,07 & 0,83 & 0,16 & 0,01 & $-0,01$ & 0,11 & $-0,07$ & $-0,20$ & $-0,10$ & 0,04 & 0,14 & 0,73 \\
\hline item 71 & 0,11 & 0,17 & $-0,03$ & 0,03 & $-0,02$ & 0,10 & $-0,03$ & $-0,06$ & 0,76 & 0,03 & 0,11 & 0,72 \\
\hline item 72 & $-0,04$ & 0,04 & 0,05 & 0,11 & 0,86 & $-0,04$ & $-0,02$ & $-0,07$ & 0,03 & 0,05 & 0,08 & 0,79 \\
\hline item 73 & $-0,04$ & 0,07 & 0,01 & 0,84 & 0,00 & $-0,05$ & 0,02 & $-0,08$ & 0,15 & 0,00 & 0,04 & 0,75 \\
\hline item 74 & 0,03 & $-0,04$ & $-0,01$ & 0,08 & 0,01 & $-0,03$ & 0,40 & 0,21 & $-0,03$ & $-0,10$ & 0,68 & 0,84 \\
\hline item 75 & $-0,05$ & 0,00 & 0,05 & $-0,01$ & 0,02 & 0,03 & 0,70 & $-0,02$ & 0,22 & 0,04 & 0,15 & 0,69 \\
\hline item 76 & $-0,07$ & 0,00 & 0,00 & 0,87 & $-0,09$ & $-0,03$ & 0,05 & $-0,02$ & 0,15 & 0,00 & 0,05 & 0,85 \\
\hline item 77 & 0,02 & 0,01 & 0,04 & 0,22 & 0,05 & $-0,01$ & 0,03 & $-0,04$ & 0,74 & 0,01 & 0,07 & 0,70 \\
\hline item 78 & 0,01 & 0,76 & 0,04 & $-0,02$ & 0,01 & $-0,03$ & $-0,01$ & 0,08 & 0,07 & 0,10 & 0,00 & 0,69 \\
\hline item 79 & $-0,05$ & 0,01 & 0,13 & 0,01 & 0,67 & 0,01 & $-0,02$ & $-0,09$ & 0,28 & 0,02 & 0,14 & 0,72 \\
\hline item 80 & $-0,01$ & 0,03 & 0,03 & 0,08 & $-0,03$ & 0,85 & 0,00 & $-0,04$ & 0,04 & 0,01 & $-0,01$ & 0,79 \\
\hline item 81 & $-0,01$ & $-0,04$ & 0,04 & $\mathbf{0 , 8 1}$ & $-0,04$ & 0,11 & $-0,03$ & 0,03 & 0,09 & 0,05 & $-0,01$ & 0,76 \\
\hline item 82 & $-0,03$ & $-0,01$ & 0,21 & 0,21 & $-0,10$ & 0,01 & $-0,08$ & 0,60 & 0,03 & 0,15 & 0,07 & 0,64 \\
\hline item 83 & $-0,03$ & 0,05 & 0,08 & 0,28 & $-0,01$ & 0,06 & $-0,03$ & 0,27 & 0,32 & 0,05 & 0,03 & 0,40 \\
\hline
\end{tabular}




\begin{tabular}{|c|c|c|c|c|c|c|c|c|c|c|c|c|}
\hline Itens & Jur & Doc & Clí & Org & Saú & Edu & Esp & $\mathbf{A P}$ & Soc & Neu & Trâ & $\mathbf{h}^{2}$ \\
\hline item 84 & $-0,01$ & $-0,04$ & 0,00 & $-0,09$ & 0,04 & $\mathbf{0 , 8 1}$ & 0,02 & 0,03 & 0,14 & $-0,01$ & 0,12 & 0,77 \\
\hline item 85 & $-0,03$ & 0,06 & $-0,07$ & $-0,03$ & 0,04 & 0,18 & 0,36 & 0,04 & 0,12 & $-0,02$ & 0,55 & 0,64 \\
\hline item 86 & 0,01 & $-0,07$ & 0,09 & $-0,14$ & $\mathbf{0 , 5 8}$ & $-0,04$ & $-0,06$ & 0,00 & 0,31 & 0,12 & 0,20 & 0,63 \\
\hline item 87 & 0,01 & $-0,07$ & 0,01 & 0,80 & 0,02 & $-0,06$ & 0,02 & 0,14 & $-0,16$ & $-0,05$ & 0,14 & 0,80 \\
\hline item 88 & 0,06 & 0,02 & 0,10 & 0,25 & $-0,05$ & $-0,05$ & 0,05 & 0,08 & 0,61 & 0,06 & $-0,06$ & 0,54 \\
\hline item 89 & 0,01 & 0,01 & 0,05 & 0,06 & 0,00 & $-0,03$ & $\mathbf{0 , 8 4}$ & 0,01 & $-0,03$ & 0,01 & 0,01 & 0,75 \\
\hline item 90 & $-0,09$ & 0,48 & 0,01 & 0,07 & $-0,01$ & $-0,03$ & 0,15 & 0,32 & 0,09 & 0,04 & 0,00 & 0,53 \\
\hline $\mathrm{N}^{\circ}$ itens & 8 & 13 & 7 & 12 & 11 & 11 & 13 & 9 & 11 & 6 & 5 & \\
\hline Alfas & 0,90 & 0,92 & 0,83 & 0,95 & 0,89 & 0,91 & 0,93 & 0,87 & 0,89 & 0,88 & 0,89 & \\
\hline$r$ teste-reteste & 0,77 & 0,88 & 0,76 & 0,89 & 0,76 & 0,85 & 0,88 & 0,84 & 0,86 & 0,78 & 0,84 & \\
\hline$M$ & 3,25 & 3,18 & 3,94 & 3,19 & 3,60 & 3,38 & 2,80 & 3,57 & 3,53 & 3,48 & 2,80 & \\
\hline$D P$ & 0,95 & 0,88 & 0,71 & 1,00 & 0,83 & 0,86 & 0,97 & 0,77 & 0,79 & 0,92 & 1,04 & \\
\hline \multicolumn{13}{|c|}{ Percentil } \\
\hline 25 (baixo) & 21 & 33 & 25 & 30 & 34 & 31 & 17 & 28 & 33 & 18 & 10 & \\
\hline 50 (médio) & 26 & 42 & 28 & 39 & 41 & 38 & 23 & 33 & 39 & 21 & 14 & \\
\hline 75 (alto) & 32 & 50 & 31 & 47 & 47 & 44 & 28 & 37 & 45 & 25 & 18 & \\
\hline \multicolumn{13}{|c|}{ Correlação entre os fatores } \\
\hline & Jur & Doc & Clí & Org & Saú & Edu & Esp & $\mathrm{AP}$ & Soc & $\mathrm{Neu}$ & Trâ & \\
\hline Jur & 1 & & & & & & & & & & & \\
\hline Doc & 0,03 & 1 & & & & & & & & & & \\
\hline Clí & 0,03 & 0,06 & 1 & & & & & & & & & \\
\hline Org & 0,12 & 0,05 & 0,10 & 1 & & & & & & & & \\
\hline Saú & 0,15 & $-0,04$ & 0,25 & 0,01 & 1 & & & & & & & \\
\hline Edu & 0,02 & 0,05 & 0,14 & 0,30 & 0,17 & 1 & & & & & & \\
\hline Esp & 0,15 & 0,10 & 0,10 & 0,41 & 0,13 & 0,32 & 1 & & & & & \\
\hline $\mathrm{AP}$ & 0,15 & 0,27 & 0,15 & 0,27 & 0,06 & 0,13 & 0,21 & 1 & & & & \\
\hline Soc & 0,16 & 0,07 & 0,11 & 0,13 & 0,27 & 0,35 & 0,25 & 0,09 & 1 & & & \\
\hline Neu & 0,14 & 0,24 & 0,19 & 0,06 & 0,15 & 0,11 & 0,18 & 0,39 & 0,03 & 1 & & \\
\hline Trâ & 0,18 & 0,05 & 0,07 & 0,33 & 0,08 & 0,14 & 0,12 & 0,16 & 0,04 & 0,06 & 1 & \\
\hline
\end{tabular}

Nota. Cargas fatoriais $\geq 0,30$ estão em negrito; $n$ do teste-reste $=60$.

Legenda Jur = Jurídica; Clí = Clínica; Doc = Docência e Pesquisa $;$ Org = Organizacional; Saú = Saúde; Edu = Educacional; Esp = Esporte; AP = Avaliação Psicológica; Soc = Social; Neu = Neuropsicologia; Trâ = Trânsito.

Essa estrutura fatorial explicou $66 \%$ da variância total dos itens, obtendo bons índices de ajuste para o modelo $(\mathrm{X} 2 / \mathrm{df}=2,45 ; \mathrm{CFI}=0,96 ; \mathrm{TLI}=0,95 ; \mathrm{RMSEA}=$ $0,04 ; \mathrm{WRMR}=0,85)$, indicando que a estrutura formada por 11 fatores é adequada para representar os dados da amostra. No que se refere aos itens, nenhum foi excluído por não apresentar cargas fatoriais menores que 0,30 . A quantidade de itens que representavam cada fator variou de cinco (Trânsito) a 13 (Docência e Esporte). A área de maior interesse da amostra total foi a área Clínica obtendo a maior média, e por outro lado, Trânsito e Esporte apresentaram as menores médias indicando o menor interesse por essas áreas na amostra deste estudo. 
As precisões por consistência interna dos fatores, foram todas excelentes, com Alfas variando de 0,83 (Clínica) a 0,95 (Organizacional). Assim como, as precisões pelo método de teste-reteste também foram todas satisfatórias, com valores de correlação acima de 0,75 para todos os fatores da escala. Sobre as correlações entre os fatores, notou-se que apenas seis foram de magnitudes moderadas, e o restante foram fracas ou nulas. Na Tabela 1 são informados os percentis dos fatores da EIAPsi divididos pelos quartis, a fim de contribuir para a interpretação dos escores do indivíduo em cada área, podendo informações de normas mais detalhadas serem verificadas em Ambiel e Martins (no prelo). Por fim, 16 itens apresentaram cargas fatoriais maiores do que $0,30 \mathrm{em}$ dois fatores. Os itens com cargas cruzadas são apresentados na íntegra na Tabela 2, juntamente com os fatores teóricos para os quais os itens foram intencionalmente construídos e os fatores que esses carregaram na ESEM.

Tabela 2. Itens que apresentaram cargas cruzadas.

\begin{tabular}{|c|c|c|}
\hline Itens & Fator teórico & Fatores com cargas $>0,30$ \\
\hline $\begin{array}{l}\text { 18. Auxiliar na decisão sobre o tratamento médico para pacientes } \\
\text { neurológicos }\end{array}$ & Neuropsicologia & Neuropsicologia $(0,59)$ e Saúde $(0,39)$ \\
\hline 19. Atuar no apoio psicológico das famílias dos detentos & Jurídica & Jurídica $(0,66)$ e Saúde $(0,30)$ \\
\hline 25. Promover a reabilitação psicossocial de indivíduos com depressão & Clínica & Clínica $(0,44)$ e Saúde $(0,37)$ \\
\hline $\begin{array}{l}\text { 33. Orientar pais ou responsáveis quanto à escolha da modalidade } \\
\text { esportiva e as implicações no ciclo de desenvolvimento da criança }\end{array}$ & Esporte & Esporte $(0,52)$ e Educacional $(0,40)$ \\
\hline 34. Realizar estágio docente & Docência & Docência $(0,61)$ e Educacional $(0,32)$ \\
\hline $\begin{array}{l}\text { 35. Participar de equipes multiprofissionais no planejamento e realização } \\
\text { das políticas de segurança para o trânsito }\end{array}$ & Trânsito & Trânsito $(0,56)$ e Esporte $(0,38)$ \\
\hline $\begin{array}{l}\text { 46. Avaliar a eficiência de programas educacionais a partir de testes } \\
\text { psicológicos e instrumentos adequados }\end{array}$ & Educacional & Educacional $(0,48)$ e Avaliação $(0,48)$ \\
\hline 47. Assessorar ONGs e cooperativas de trabalho & Social & Social $(0,52)$ e Organizacional $(0,34)$ \\
\hline 53. Analisar os diferentes fatores envolvidos em acidentes de trânsito & Trânsito & Trânsito $(0,51)$ e Esporte $(0,39)$ \\
\hline $\begin{array}{l}\text { 57. Envolver-se em pesquisas que ampliam o conhecimento psicológico } \\
\text { aplicado ao direito }\end{array}$ & Jurídica & Jurídica $(0,50)$ e Docência $(0,33)$ \\
\hline 62. Atuar em dispositivos de saúde pública & Saúde & Social $(0,47)$ e Saúde $(0,42)$ \\
\hline $\begin{array}{l}\text { 68. Atuar como perito em exames de habilitação, reabilitação ou } \\
\text { readaptação profissional do motorista }\end{array}$ & Trânsito & Trânsito $(0,67)$ e Esporte $(0,38)$ \\
\hline $\begin{array}{l}\text { 74. Avaliar capacidades, habilidades e aptidões de candidatos à carteira } \\
\text { de motorista }\end{array}$ & Trânsito & Trânsito $(0,68)$ e Esporte $(0,40)$ \\
\hline $\begin{array}{l}\text { 85. Elaborar e implantar programas de saúde, educação e segurança do } \\
\text { trânsito }\end{array}$ & Trânsito & Trânsito $(0,55)$ e Esporte $(0,36)$ \\
\hline $\begin{array}{l}\text { 86. Atuar em centros e postos de saúde na comunidade, hospitais, clínica } \\
\text { psiquiátricas ou de atendimento à saúde mental }\end{array}$ & Saúde & Saúde $(0,58)$ e Social $(0,31)$ \\
\hline 90. Realizar coletas de dados utilizando diferentes técnicas & Docência & Docência $(0,48)$ e Avaliação $(0,32)$ \\
\hline
\end{tabular}


Nota-se na Tabela 2 que exceto o item 62, os demais apresentaram as maiores magnitudes das cargas fatoriais nos fatores que os itens foram teoricamente construídos para representar. Além disso, foi visto também que as segundas cargas fatoriais dos itens variaram, em grande parte, entre 0,30 a 0,40 , havendo apenas os itens 46 e 62 que apresentaram cargas fatoriais de 0,48 e 0,42 , respectivamente. Esse resultado indica que na maioria dos casos houve uma segunda carga fatorial baixa, ou seja, próxima do limite aceitável $(0,30)$. Outro resultado relevante para compreensão dos dados se refere ao fato de que todos os itens que representam o fator Trânsito (itens 35, 53, 68, 74 e 85), apresentaram maiores cargas no fator Trânsito e também, em todos os casos, no fator Esporte, sendo nesses casos sempre com menores magnitudes. Sendo assim, a decisão adotada pelos autores foi pela manutenção de 11 dos 15 itens como representantes de ambos os fatores que esses carregaram, excluindo desses os cinco itens de Trânsito (itens 35, 53, 68, 74 e 85), devido à inconsistência teórica das cargas cruzadas com o fator Esporte.

Em seguida, foram verificadas as diferenças de médias dos interesses por áreas da Psicologia, bem como os conceitos secundários, elevação dos interesses e a nitidez do perfil dos interesses, em relação ao sexo dos estudantes. A análise indicou que os fatores Saúde ( $t=$ $2,87 ; p=0,01)$ e Jurídica $(t=2,37 ; p=0,02)$ apresentaram diferenças significativa entre os sexos, com tamanhos de efeito considerados fracos $(d=0,24 ; d=0,20$, respectivamente), no qual as mulheres $(M=3,59 ; D P=0,85 ; M$ $=3,28 ; D P=0,95$, respectivamente) apresentaram uma pontuação maior em comparação com os homens $(M=$ 3,$38 ; D P=0,93 ; M=3,09 ; D P=0,93$, respectivamente). Por outro lado, o fator Docência e Pesquisa também apresentou diferença significativa $(t=5,76 ; p=0,01)$ e com tamanho de efeito fraco $(d=0,48)$, com os homens $(M$ $=3,52 ; D P=0,81)$ pontuando mais do que as mulheres $(M=3,10 ; D P=0,88)$. A elevação $(t=0,21 ; p=0,83) \mathrm{e}$ a nitidez $(t=1,60 ; p=0,11)$ não apresentaram diferenças significativas em relação ao sexo dos participantes.
Para analisar as diferenças nos períodos do curso, os participantes foram agrupados da seguinte forma: início do curso foi representado pelos participantes do $1 .^{\circ}$ e 2 . $^{\circ}$ ano, o meio do curso foi representado pelos participantes do $3 .^{\circ}$ ano e o fim do curso pelos participantes do $4 .^{\circ}$ e 5. ano. A seguir, na Tabela 3, são descritas as diferenças que foram significativas nos fatores de interesses por áreas da Psicologia, bem como na elevação e na nitidez dos estudantes divididos pelo período do curso.

Tabela 3. Diferenças de médias nos interesses por áreas da Psicologia referentes ao período do curso.

\begin{tabular}{|c|c|c|c|c|c|c|}
\hline \multirow[b]{2}{*}{ Fator } & \multirow[b]{2}{*}{$F^{*}$} & \multirow[b]{2}{*}{$p$} & \multirow[b]{2}{*}{ Período } & \multicolumn{3}{|c|}{ Subconjuntos } \\
\hline & & & & 1 & 2 & 3 \\
\hline \multirow[t]{3}{*}{ Educacional } & 5,06 & 0,01 & Fim & 3,28 & & \\
\hline & & & Meio & 3,40 & 3,40 & \\
\hline & & & Início & & 3,49 & \\
\hline \multirow[t]{3}{*}{ Saúde } & 3,99 & 0,02 & Fim & 3,45 & & \\
\hline & & & Meio & & 3,61 & \\
\hline & & & Início & & 3,62 & \\
\hline \multirow[t]{3}{*}{ Jurídica } & 5,21 & 0,01 & Fim & 3,15 & & \\
\hline & & & Meio & 3,22 & & \\
\hline & & & Início & & 3,40 & \\
\hline \multirow[t]{3}{*}{ Neuropsicologia } & 17,42 & 0,01 & Fim & 3,29 & & \\
\hline & & & Meio & & 3,46 & \\
\hline & & & Início & & & 3,72 \\
\hline \multirow[t]{3}{*}{ Elevação } & 4,01 & 0,02 & Fim & 3,27 & & \\
\hline & & & Meio & 3,35 & 3,35 & \\
\hline & & & Início & & 3,39 & \\
\hline \multirow[t]{3}{*}{ Nitidez } & 9,01 & 0,01 & Início & 0,72 & & \\
\hline & & & Meio & 0,75 & & \\
\hline & & & Fim & & 0,81 & \\
\hline
\end{tabular}

Nota. ${ }^{*} g l=2 . \mathrm{n}$ início $=294 ; \mathrm{n}$ meio $=318 ; \mathrm{n}$ fim $=349$. 
Na Tabela 3 é possível observar que em todos os casos significativos quem estava cursando os períodos iniciais do curso de Psicologia apresentou maior nível de interesses pelas áreas Educacional, Saúde, Jurídica e Neuropsicologia, em comparação com os estudantes que cursavam os períodos finais do curso. Referente aos conceitos secundários dos interesses, elevação e nitidez, nota-se que os estudantes dos anos iniciais demonstram um perfil dos interesses por áreas da Psicologia mais elevado em comparação com os estudantes do fim do curso. A respeito da nitidez é possível observar o contrário, no qual os alunos do fim do curso apresentaram maior nitidez.

\section{Discussão}

O objetivo do presente estudo foi buscar evidências de validade baseadas na estrutura interna e estimativas de precisão para a EIAPsi, assim como verificar diferenças nas médias dos interesses por áreas da Psicologia dos participantes divididos pelo sexo e período do curso. Os resultados apontaram para satisfatórias evidências de validade e boas estimativas de precisão por consistência interna dos fatores e pelo método teste-reteste para a EIAPsi. Também foram identificadas diferenças significativas nos interesses em relação ao sexo e período do curso.

A estrutura teórica da EIAPsi formada por $11 \mathrm{fa}-$ tores representou de forma adequada os dados, sendo obtidos bons índices de ajuste, replicando assim outros resultados anteriores (Ambiel \& Martins, 2016a; Ambiel et al., no prelo). Porém, essa não foi a melhor estrutura fatorial indicada por nenhum dos três métodos de retenção fatorial (VSS, MAP e Análise Paralela). Entretanto, ao verificar a coerência teórica das cargas fatoriais e as excelentes precisões por consistência interna dos fatores, foi possível adotar essa como a melhor estrutura para a escala.

Além disso, como apontado na literatura, os interesses profissionais consistem em traços relativamente estáveis ao longo do tempo (Low \& Rounds, 2007; Rounds \& Su, 2014; Schultz et al., 2017). Por meio da evidência inicial apresentada no presente estudo, essa definição pode também ser corroborada no caso dos interesses básicos por áreas da Psicologia, devido aos satisfatórios índices de precisão apontados no método teste-reteste. Esse resultado favorece que a EIAPsi seja empregada em programas de intervenção de carreira, uma vez que o instrumento demonstrou boa confiabilidade no decorrer de um mês.

A respeito da média dos interesses, foi visto nessa amostra que os estudantes apresentaram mais interesse pela área Clínica e menos interesse pelas áreas do Trânsito e do Esporte. Esse resultado indica uma continuidade na preferência dos interesses, evidenciada em estudos anteriores, com maior interesse dos estudantes pela área Clínica (Ambiel \& Martins, 2016; Ambiel et al., no prelo; Campos et al., 1999; Ferreira et al., 2015; Magalhães et al., 2001; Rodrigues et al., 2013; Souza \& Souza, 2012). As correlações entre os fatores foram todas de magnitudes nulas, fracas ou no máximo moderadas, indicando independência entre os fatores, o que pode ser considerada uma evidência de que essas áreas realmente se diferem entre si.

No que tange aos 16 itens que apresentaram cargas cruzadas, notou-se que os cinco itens representantes do fator Trânsito também apresentaram no fator esporte a segunda maior carga fatorial. Devido à falta de sentido teórico para explicação desse resultado, esse pode ser interpretado como sendo efeito do baixo interesse geral apresentado pela amostra nesses dois fatores. Além disso, apesar de todos os itens do fator Trânsito terem cargas cruzadas com o fator Esporte, a correlação entre os fatores foi positiva de magnitude fraca e próxima de nula $(r=0,12)$, indicando haver pouca relação entre as duas áreas. Portanto, sugere-se que estudos futuros sejam realizados com amostras mais robustas a fim de controlar os níveis de interesse dos participantes a respeito dessas duas áreas, contando assim com uma amostra mais representativa de participantes que se interessam por ambas as áreas. Por meio desse controle amostral, será possível verificar com mais rigor se as cargas cruzadas 
obtidas neste estudo são reflexo da amostra ou se de fato os estudantes compreendem as atividades profissionais contidas nos itens de Trânsito como também sendo atuações dos profissionais da área do Esporte.

Outra preocupação constatada por meio da baixa média nestas áreas consiste no possível baixo estímulo das instituições de ensino sobre essas áreas. Nesse sentido, assim como Souza e Souza (2012) apontam, são necessárias experiências práticas nos estágios para maior embasamento nas escolhas realizadas pelo estudante, devendo essas experiências ser proporcionadas pelas instituições formadoras. Em contrapartida, nos demais 11 itens que apresentaram cargas cruzadas, notou-se que os conteúdos semânticos dos itens representam teoricamente atividades profissionais presentes nos seus respectivos fatores. Sendo assim, essa é uma evidência empírica de que os estudantes de Psicologia consideram algumas atividades profissionais possíveis de serem realizadas por profissionais de diferentes áreas.

Sobre as diferenças nos interesses por áreas da Psicologia em relação ao sexo dos participantes foi visto que as mulheres pontuaram mais que os homens nas áreas Saúde e Jurídica. Por outro lado, os homens pontuaram mais que as mulheres na área Docência e Pesquisa. Esses resultados parecem estar indo da mesma direção do que a literatura internacional tem apresentado sobre os interesses dos homens e das mulheres, sendo os homens mais interessados por coisas, ciência e números (Docência e Pesquisa) e as mulheres preferindo atividades que possibilitem trabalharem com pessoas (Saúde e Jurídica) (Hoff et al., 2018; Su et al., 2009).

Por sua vez, as diferenças obtidas em relação ao período do curso do estudante de Psicologia, indicaram que estudantes do início do curso apresentaram maior interesse pelas áreas Educacional, Saúde, Jurídica e Neuropsicologia, em comparação com os estudantes do fim do curso. Esse resultado pode estar refletindo que essas áreas são mais atrativas no início do curso e acabam deixando de ser interessantes no fim, talvez pela falta de experiências ou por experiências malsucedidas nos estágios. Complementarmente, foram verificadas as diferenças do período do curso também nos conceitos secundários elevação e nitidez. No caso da elevação os alunos com maior pontuação estavam no início do curso se diferenciando significativamente de quem cursava os períodos finais. Portanto, os resultados parecem indicar que com o passar dos anos cursados, os estudantes de Psicologia têm os seus interesses gerais pela Psicologia diminuídos. Nesse sentido, abre-se uma nova agenda de pesquisa que busque verificar as variações dos interesses dos estudantes no decorrer do curso de Psicologia, uma vez que o presente estudo verificou essa variação de forma transversal.

Por outro lado, a nitidez dos interesses dos participantes foi maior no fim do curso em comparação com o início e meio do curso, indicando que estudantes mais próximos do fim do curso discriminam melhor as áreas dentro da Psicologia que mais se interessam daquelas que menos se interessam. Esse resultado pode ser encarado como uma evidência de validade de critério para a EIAPsi, uma vez que era esperado que estudantes do fim do curso, após terem passado pelas experiências profissionais dos estágios, conseguissem ter maior discernimento no momento da escolha pelas áreas de atuação (Souza \& Souza, 2012).

\section{Considerações finais}

A amostra do presente artigo representou de forma semelhante as características dos estudantes de Psicologia que participaram do ENADE em 2015, sendo a maioria, em ambos os casos, do sexo feminino $\left(f_{\text {enade }}=83 \% ; f_{\text {estudo }}\right.$ $=80,7 \%)$, de instituições particulares $\left(f_{\text {enade }}=81,9 \% ; f_{\text {estudo }}\right.$ $=89,3 \%)$ e localizadas nas regiões Sudeste e Sul $\left(f_{\text {enade }}\right.$ $=66,7 \% ; f_{\text {estudo }}=85 \%$ ) (Instituto Nacional de Estudos e Pesquisas Educacionais Anísio Teixeira [INEP], 2015). Contudo, como neste artigo foram verificadas as diferenças entre os sexos e os dois grupos (masculino e feminino) foram representados por tamanhos amostrais bastante distintos, constata-se uma limitação, a qual pode ser 
mais bem explorada em novos estudos que visem uma maior igualdade entre os representantes de cada sexo.

Apesar de haver diferença na quantidade de itens por fator, variando de cinco a 13 itens, as precisões de todos os fatores não foram impactadas pelo número de itens, mesmo essa sendo uma das fontes de influências nos alfas (Peterson, 1994). Sendo assim, sugere-se que em estudos futuros sejam verificas as propriedades psicométricas do instrumento com uma quantidade balanceada de itens. A decisão dos autores do presente artigo pela manutenção dos 90 itens, ocorreu por acreditarem que dessa forma o instrumento possibilita maior compreensão da dinâmica dos interesses dos estudantes de Psicologia, corroborando assim para a sua aplicação em intervenções.

Este artigo visou apresentar os estudos psicométricos da EIAPsi, que se configura como um potencial instrumento para profissionais e instituições de Ensino Superior que visem realizar intervenções sobre escolha de carreira dentro das áreas de atuação existentes na profissão de Psicologia. Nesse sentido, foram evidenciadas boas propriedades psicométricas para a EIAPsi, especialmente no que se refere às evidências de validade baseadas na estrutura interna e nas estimativas de precisão por consistência interna e por teste-reteste. Além disso, o estudo pôde contribuir com resultados exploratórios a respeito do impacto do sexo e do período do curso sobre os interesses dos estudantes de Psicologia. Foi também apontado algumas atividades profissionais, que segundo a forma como estudantes expressaram seus interesses, podem estar indicando atuações desempenhadas por profissionais de duas áreas da Psicologia, devendo novos estudos serem desenvolvidos nesse sentido.

\section{Referências}

Ambiel, R. A. M., \& Martins, G. H. (2016a). Interesses profissionais expressos e inventariados de estudantes de Psicologia: Implicações para a formação. Psicologia Ensino \& Formação, 7(1), 5-17. https://doi. org/10.21826/2179-5800201671517
Ambiel, R. A. M., \& Martins, G. H. (2016b). Escala de Interesses por Áreas da Psicologia. Relatório técnico não publicado. "(DOI INEXISTENTE)"

Ambiel, R. A. M., \& Martins, G. H. (no prelo). Escala de Interesses por Áreas da Psicologia. Em A. Andrade, M. F. O. Nunes, M. Z. Oliveira, \& R. A. M. Ambiel, Técnicas e Medidas em Orientação Profissional e de Carreira. São Paulo, SP: Vetor. "(DOI INEXISTENTE)"

Ambiel, R. A. M., Martins, G. H., Taveira, M. C., Zuanazzi, A. C., Silveira, J. Z., \& Cicchetto, A. A. (no prelo). Estudo psicométrico da Escala de Interesses por Áreas da Psicologia - Versão Portuguesa. Paidéia. "(DOI INEXISTENTE)"

Andrade, A. L., Pissaia, A. T., Oliveira, M. Z., \& Silva, M. Z. (2016). Características proteanas e afetos sobre carreira de estudantes de Psicologia. Estudos de Psicologia (Campinas), 33(4), 677-688. https://doi. org/10.1590/1982-02752016000400011

Andrade, A., Tiraboschi, G. A., Antunes, N. A., Viana, P. V. B. A., Zanoto, P. A., \& Curilla, R. T. (2016). Vivências acadêmicas e sofrimento psíquico de estudantes de Psicologia. Psicologia Ciência e Profissão, 36(4), 831-846. https://doi.org/10.1590/1982-3703004142015

Bueno, J. M. H., Lemos, C. G., \& Tomé, F. A. M. F. (2004). Interesses profissionais de um grupo de estudantes de Psicologia e suas relações com inteligência e personalidade. Psicologia em Estudo, 9(2), 271-278. https://doi.org/10.1590/S1413-73722004000200013

Bullock, E. E. \& Reardon, R. C. (2008). Interest profile elevation, Big Five personality traits, and secondary constructs on the Self-Directed Search: A replication and extension. Journal of Career Assessment, 16(3), 326-338. https://doi.org/10.1177/1069072708317379

Campos, L. F. D. L., Catão, E. C., \& Fujii, C. M. (1999). Inventário cientista-prático de orientação profissional em Psicologia: Um estudo exploratório. Psicologia Escolar e Educacional, 3(2), 139-150. https://doi.org/10.1590/ $\underline{\text { S1413-85571999000200004 }}$

Cohen, J. (1992). A power primer. Psychological Bulletin, 112(1). 155-159. https://doi.org/10.1037/0033$\underline{\text { 2909.112.1.155 }}$

Daltro, M. R., \& Pondé, M. P. (2017). How candidates for psychology course feel that the right choice? International Journal of Health Education, 1(1), 23-30. https://oi.org/10.17267/2594-7907ijhe.vli1.1359 
Ferreira, A. I., Rodrigues, R. I., \& Ferreira, P. C. (2015). Career interests of students in psychology specialties degrees: psychometric evidence and correlations with the RIASEC dimensions. International Journal for Educational and Vocational Guidance, 16(1), 91-111. https://doi.org/10.1007/s10775-015-9289-3

Hernández-Franco, V., Baena, B. C., Prieto-Ursúa, M., \& Toro, L. B. (2018). "Quiero estudiar Psicología": Intereses y valores vocacionales de los alumnos de Bachillerato con preferencia por los estudios de Psicología. Electronic Journal of Research in Education Psychology, 16(44), 175-198. https://doi.org/10.25115/ejrep.v16i44.1943

Hoff, K. A., Briley, D. A., Wee, C. J., \& Rounds, J. (2018). Normative changes in interests from adolescence to adulthood: A meta-analysis of longitudinal studies. Psychological Bulletin, 144(4), 426-451. https://doi. org $/ 10.1037 /$ bu10000140

Holland, J. L. (1997). Making Vocational Choices: A theory of vocational personalities and work environments (3a. ed.). Englewood Cliffs, NJ: Prentice Hall. “(DOI INEXISTENTE)"

Hu, L., \& Bentler, P. M. (1999). Cutoff criteria for fit indexes in covariance structure analysis: Conventional criteria versus new alternatives. Structural Equation Modeling: A Multidisciplinary Journal, 6(1), 1-55. https://doi.org/10.1080/10705519909540118

Im, S. (2011). The effect of profile elevation on the relationship between interest differentiation and vocational identity. British Journal of Guidance \& Counselling, 39(2), 149-160. https://doi.org/10.1080/03069885.2010.547054

Instituto Nacional de Estudos e Pesquisas Educacionais Anísio Teixeira (2015). ENADE 2015: Relatório sintese de área Psicologia. Brasília: INEP. "(DOI INEXISTENTE)"

Jaensch, V. K., Hirschi, A., \& Spurk, D. (2016). Relationships of vocational interest congruence, differentiation, and elevation to career preparedness among university students. German Journal of Work and Organizational Psychology, 60, 79-89. https://doi. org/10.1026/0932-4089/a000210

Lamas, K. C. A. (2017). Conceito e relevância dos interesses profissionais no desenvolvimento de carreira: Estudo teórico. Temas em Psicologia, 25(2), 703-717. https://doi.org/10.9788/TP2017.2-16Pt
Lent, R. W., Brown, S. D., \& Hackett, G. (1994). Toward a unifying social cognitive theory of career and academic interest, choice, and performance. Journal of Vocational Behavior, 45(1), 79-122. https:// doi.org/10.1006/jvbe.1994.1027

Low, K. S., \& Rounds, J. (2007). Interest change and continuity from early adolescence to middle adulthood. International Journal for Educational and Vocational Guidance, 7(1), 23-36. https://doi.org/10.1007/ s10775-006-9110-4

Magalhães, M. O., Straliotto, M., Keller, M., \& Gomes, W. B. (2001). Eu quero ajudar as pessoas: A escolha vocacional da Psicologia. Psicologia: Ciência e Profissão, 21(2), 10-27. https://doi.org/10.1590/S1414$\underline{98932001000200003}$

Martins, G. H., Hernández, D. N., \& Ambiel, R. A. M. (2014). Validade de conteúdo para a Escala de Interesses por Áreas da Psicologia. Trabalho apresentado na modalidade painel, no IV Congresso Brasileiro Psicologia: Ciência e Profissão, Uninove, São Paulo, SP. “(DOI INEXISTENTE)"

Noronha, A. P. P., \& Ambiel, R. A. M. (2005). Level of differentiation of vocational interests profiles: Comparative study by age and schooling in a brazilian sample. Paidéia, 25(60), 49-56. http://dx.doi. org/10.1590/1982-43272560201507

Nunnally, J. C. (1978). Psychometric theory. New York: McGraw-Hill Inc. "(DOI INEXISTENTE)"

Peterson, R. A. (1994). A meta-analysis of Cronbach's coefficient alpha. Journal of Consumer Research, 21(2), 381-391. https://doi.org/10.1086/209405

Rabelo, A. L. A., Pilati, R., \& Porto, J. B. (2016). O Teste de Associação Implícita para avaliação da preferência profissional em Psicologia. Revista Brasileira de Orientação Profissional, 17(2). Recuperado de http:// www.redalyc.org/html/2030/203051246007/

Rodrigues, R. I., Ferreira, A. I., \& Bártolo-Ribeiro, R. (2013). Construção e desenvolvimento de um questionário de interesses para a psicologia. Revista Iberoamericana de Diagnóstico y Evaluación/e Avaliaçao Psicológica, 2(36), 99-116. Recupera de http://aidep.org/03 ridep/R36/Art.\%205.pdf 
Rounds, J., \& Su, R. (2014). The nature and power of interests. Current Directions in Psychological Science, 23(2), 98-103. https://doi.org/10.1177/0963721414522812

Schultz, L. H., Connolly, J. J., Garrison, S. M., Leveille, M. M., \& Jackson, J. J. (2017). Vocational interests across 20 years of adulthood: Stability, change, and the role of work experiences. Journal of Research in Personality, 71, 46-56. https://doi.org/10.1016/j.jrp.2017.08.010

Souza, M. F., \& Souza, R. L. (2012). O processo de escolha da área de atuação pelo graduando de Psicologia. Revista Kaleidoscópio, 3, 36-58. Recuperado de https:// www.unilestemg.br/kaleidoscopio/artigos/volume3/ processo de escolha da area.pdf

Su, R., Rounds, J., \& Armstrong, P. I. (2009). Men and things, women and people: A meta-analysis of sex differences in interests. Psychological Bulletin, 135(6), 859-884. https://doi.org/10.1037/a0017364

Recebido em: 21/12/2018.

Aprovado em: 18/7/2019.

Publicado em: $\mathrm{xx} / \mathrm{x} / \mathrm{xxxx}$
Endereço para correspondência: Rodolfo Augusto Matteo Ambiel (Rua Waldemar César da Silveira, 105, Vila Cura D’Ars, Campinas, SP, Brasil, 13045510; (19)3779-3300; rodolfo.ambiel@usf.edu.br).

\section{Nome: Rodolfo Augusto Matteo Ambiel}

E-mail: rodolfo.ambiel@usf.edu.br

Titulação Acadêmica: Doutor em Psicologia

Afiliação Institucional: Universidade São Francisco (USF)

\section{Nome: Gustavo Henrique Martins}

E-mail: gustavoh.martins95@gmail.com

Titulação Acadêmica: Mestrando em Psicologia

Afiliação Institucional: Universidade São Francisco (USF)

Apoio: CNPq e CAPES (código de financiamento 001)

\section{Anexo:}

\section{Escala de Interesses por Áreas da Psicologia - EIAPsi}

Rodolfo Augusto Matteo Ambiel e Gustavo Henrique Martins

A seguir, você encontrará algumas atividades que os psicólogos podem exercer profissionalmente. Leia atentamente cada uma e marque quanto você gosta ou gostaria de exercer cada atividade (lembrando que você poderá marcar qualquer uma das opções):

\begin{tabular}{|c|c|c|c|c|}
\hline $\begin{array}{c}\text { Detesto/detestaria } \\
\text { exercer essa atividade }\end{array}$ & $\begin{array}{c}\text { Não gosto/não } \\
\text { gostaria de exercer } \\
\text { essa atividade }\end{array}$ & $\begin{array}{c}\text { Imparcial/neutro(a) a } \\
\text { esta atividade }\end{array}$ & $\begin{array}{c}\text { Gosto/gostaria de } \\
\text { exercer essa atividade }\end{array}$ & $\begin{array}{c}\text { Adoro/adoraria } \\
\text { exercer essa atividade }\end{array}$ \\
\hline 1 & 2 & 3 & 4 & 5 \\
\hline
\end{tabular}




\begin{tabular}{|c|c|c|c|c|c|}
\hline Publicar artigos científicos & 1 & 2 & 3 & 4 & 5 \\
\hline Conhecer e aplicar diversos testes psicológicos & 1 & 2 & 3 & 4 & 5 \\
\hline Atuar com indivíduos em situação de processos judiciais & 1 & 2 & 3 & 4 & 5 \\
\hline Compreender as relações do funcionamento cerebral com o comportamento & 1 & 2 & 3 & 4 & 5 \\
\hline Atuar na compreensão da construção social da subjetividade dos sujeitos & 1 & 2 & 3 & 4 & 5 \\
\hline Elaborar laudos sobre o funcionamento mental dos indivíduos em processos judiciais & 1 & 2 & 3 & 4 & 5 \\
\hline Propor projetos de pesquisa inovadores para responder questões da psicologia & 1 & 2 & 3 & 4 & 5 \\
\hline Realizar atendimentos psicoterapêuticos em consultórios ou clínicas particulares & 1 & 2 & 3 & 4 & 5 \\
\hline Auxiliar nos processos de ensino-aprendizagem & 1 & 2 & 3 & 4 & 5 \\
\hline Colaborar na formulação de políticas penais & 1 & 2 & 3 & 4 & 5 \\
\hline Atender famílias com pacientes em estado terminal, auxiliando no processo de aceitação & 1 & 2 & 3 & 4 & 5 \\
\hline Desenvolver jogos e atividades para avaliação, prevenção e reabilitação neuropsicológica & 1 & 2 & 3 & 4 & 5 \\
\hline Trabalhar em ONGs garantindo suporte psicológico aos seus integrantes & 1 & 2 & 3 & 4 & 5 \\
\hline Escrever relatos e artigos científicos & 1 & 2 & 3 & 4 & 5 \\
\hline Fazer a avaliação de detentos em liberdade condicional & 1 & 2 & 3 & 4 & 5 \\
\hline Realizar avaliações para se chegar a um psicodiagnóstico & 1 & 2 & 3 & 4 & 5 \\
\hline Intervir em situações de conflitos entre funcionários & 1 & 2 & 3 & 4 & 5 \\
\hline Auxiliar na decisão sobre o tratamento médico para pacientes neurológicos & 1 & 2 & 3 & 4 & 5 \\
\hline Atuar no apoio psicológico das famílias dos detentos & 1 & 2 & 3 & 4 & 5 \\
\hline Trabalhar na integração família-comunidade-escola & 1 & 2 & 3 & 4 & 5 \\
\hline Redigir documentos relatando resultados de procedimentos de avaliação & 1 & 2 & 3 & 4 & 5 \\
\hline Realizar pesquisas no âmbito social e comunitário & 1 & 2 & 3 & 4 & 5 \\
\hline Ajudar na integração da população em atividades físicas & 1 & 2 & 3 & 4 & 5 \\
\hline Facilitar o desenvolvimento e integração de alunos no âmbito escolar & 1 & 2 & 3 & 4 & 5 \\
\hline Promover a reabilitação psicossocial de indivíduos com depressão & 1 & 2 & 3 & 4 & 5 \\
\hline Promover atividades que os internos possam realizar em estabelecimentos penais & 1 & 2 & 3 & 4 & 5 \\
\hline Atuar junto a pacientes terminais hospitalizados & 1 & 2 & 3 & 4 & 5 \\
\hline Atualizar-se constantemente em relação à literatura científica & 1 & 2 & 3 & 4 & 5 \\
\hline Colaborar na integração dos trabalhadores com novos equipamentos ou equipes de tr & 1 & 2 & 3 & 4 & 5 \\
\hline
\end{tabular}




\begin{tabular}{|c|c|c|c|c|c|}
\hline Supervisionar outros psicólogos clínicos & 1 & 2 & 3 & 4 & 5 \\
\hline Ajudar pessoas que sofreram de algum tipo de acidente & 1 & 2 & 3 & 4 & 5 \\
\hline Auxiliar no bem-estar do trabalhador & 1 & 2 & 3 & 4 & 5 \\
\hline $\begin{array}{l}\text { Orientar pais ou responsáveis quanto à escolha da modalidade esportiva e as implicações no ciclo de } \\
\text { desenvolvimento da criança }\end{array}$ & 1 & 2 & 3 & 4 & 5 \\
\hline Realizar estágio docente & 1 & 2 & 3 & 4 & 5 \\
\hline $\begin{array}{l}\text { Participar de equipes multiprofissionais no planejamento e realização das políticas de segurança para o } \\
\text { trânsito }\end{array}$ & 1 & 2 & 3 & 4 & 5 \\
\hline Realizar atendimentos psicoterapêuticos com indivíduos, casais, famílias e grupos & 1 & 2 & 3 & 4 & 5 \\
\hline Auxiliar na avaliação e orientação em audiências de conciliação & 1 & 2 & 3 & 4 & 5 \\
\hline Atuar na atenção a grupos em situação de vulnerabilidade em centros comunitários & 1 & 2 & 3 & 4 & 5 \\
\hline $\begin{array}{l}\text { Colaborar para a compreensão e transformação das relações inter e intrapessoais que ocorrem nos } \\
\text { ambientes esportivos }\end{array}$ & 1 & 2 & 3 & 4 & 5 \\
\hline Elaborar problemas de pesquisa e hipóteses & 1 & 2 & 3 & 4 & 5 \\
\hline Trabalhar em empresas & 1 & 2 & 3 & 4 & 5 \\
\hline Analisar os diversos segmentos do sistema educacional & 1 & 2 & 3 & 4 & 5 \\
\hline Realizar atendimentos com o intuito de preparar o atleta para o desempenho da atividade & 1 & 2 & 3 & 4 & 5 \\
\hline Intervir nos fenômenos psicológicos do indivíduo & 1 & 2 & 3 & 4 & 5 \\
\hline Elaborar e implementar treinamentos de habilidades profissionais & 1 & 2 & 3 & 4 & 5 \\
\hline Avaliar a eficiência de programas educacionais a partir de testes psicológicos e instrumentos adequados & 1 & 2 & 3 & 4 & 5 \\
\hline Assessorar ONGs e cooperativas de trabalho & 1 & 2 & 3 & 4 & 5 \\
\hline Ministrar aulas sobre conteúdos específicos & 1 & 2 & 3 & 4 & 5 \\
\hline Dar devolutivas de avaliações & 1 & 2 & 3 & 4 & 5 \\
\hline Atender pessoas que passaram por um grande desastre & 1 & 2 & 3 & 4 & 5 \\
\hline Aplicar instrumentos para determinação de perfil, individual e coletivo, para a prática esportiva & 1 & 2 & 3 & 4 & 5 \\
\hline Elaborar um plano de tratamento para reabilitação neuropsicológica do paciente & 1 & 2 & 3 & 4 & 5 \\
\hline Analisar os diferentes fatores envolvidos em acidentes de trânsito & 1 & 2 & 3 & 4 & 5 \\
\hline Orientar trabalhos de alunos de iniciação científica, mestrado e doutorado & 1 & 2 & 3 & 4 & 5 \\
\hline Responsabilizar-se em melhorar as condições de trabalho na organização & 1 & 2 & 3 & 4 & 5 \\
\hline Atender a pacientes/clientes com base em uma abordagem teórica específica & 1 & 2 & 3 & 4 & 5 \\
\hline Envolver-se em pesquisas que ampliam o conhecimento psicológico aplicado ao direito & 1 & 2 & 3 & 4 & 5 \\
\hline
\end{tabular}


PSICO (PORTO ALEGRE) | V. 50, N. $4 \mid$ e-32840

\begin{tabular}{|c|c|c|c|c|c|}
\hline Saber selecionar adequadamente instrumentos para diferentes situações de avaliação & 1 & 2 & 3 & 4 & 5 \\
\hline Realizar avaliação das funções neuropsicológicas & 1 & 2 & 3 & 4 & 5 \\
\hline Orientar a aplicação de programas específicos de ensino para indivíduos com necessidades especiais & 1 & 2 & 3 & 4 & 5 \\
\hline Realizar análises estatísticas & 1 & 2 & 3 & 4 & 5 \\
\hline Atuar em dispositivos de saúde pública & 1 & 2 & 3 & 4 & 5 \\
\hline Trabalhar com crianças com dificuldade e/ou atrasos no desenvolvimento global & 1 & 2 & 3 & 4 & 5 \\
\hline Participar do processo de desligamento de funcionários da empresa & 1 & 2 & 3 & 4 & 5 \\
\hline Ajudar atletas, técnicos e comissões técnicas a alcançarem um nível ótimo de saúde mental & 1 & 2 & 3 & 4 & 5 \\
\hline Planejar processos de avaliação em diversos contextos de atuação & 1 & 2 & 3 & 4 & 5 \\
\hline Utilizar diversas técnicas para melhorar a eficiência das práticas psicoterapêuticas & 1 & 2 & 3 & 4 & 5 \\
\hline Atuar como perito em exames de habilitação, reabilitação ou readaptação profissional do motorista & 1 & 2 & 3 & 4 & 5 \\
\hline Realizar trabalhos de investigação clínica utilizando testes e exercícios neuropsicológicos & 1 & 2 & 3 & 4 & 5 \\
\hline Participar de bancas de defesa de mestrado e doutorado & 1 & 2 & 3 & 4 & 5 \\
\hline Planejar, avaliar e executar políticas públicas e programas comunitários & 1 & 2 & 3 & 4 & 5 \\
\hline Auxiliar na preparação de pacientes para entrada, permanência e alta hospitalar & 1 & 2 & 3 & 4 & 5 \\
\hline Compreender o significado subjetivo atribuído pelos funcionários ao trabalho exercido & 1 & 2 & 3 & 4 & 5 \\
\hline Avaliar capacidades, habilidades e aptidões de candidatos à carteira de motorista & 1 & 2 & 3 & 4 & 5 \\
\hline Colaborar para a adesão e participação da população em geral em programas de atividades físicas & 1 & 2 & 3 & 4 & 5 \\
\hline Trabalhar com as relações entre os sujeitos existentes no ambiente de trabalho & 1 & 2 & 3 & 4 & 5 \\
\hline Mediar às intervenções de equipes multiprofissionais nos contextos comunitários & 1 & 2 & 3 & 4 & 5 \\
\hline Dar pareceres de manuscritos para as revistas científicas da área & 1 & 2 & 3 & 4 & 5 \\
\hline Assistir o paciente, sua família e a equipe de saúde dentro de uma unidade de saúde & 1 & 2 & 3 & 4 & 5 \\
\hline Analisar e intervir no clima educacional & 1 & 2 & 3 & 4 & 5 \\
\hline Facilitar as relações entre pessoas e organizações, contribuindo para o desenvolvimento de ambas & 1 & 2 & 3 & 4 & 5 \\
\hline Possibilitar a tomada de decisão a partir de avaliações & 1 & 2 & 3 & 4 & 5 \\
\hline Privilegiar os processos grupais nas avaliações e intervenções & 1 & 2 & 3 & 4 & 5 \\
\hline Atuar preventivamente nas creches, escolas e escolas especiais & 1 & 2 & 3 & 4 & 5 \\
\hline Elaborar e implantar programas de saúde, educação e segurança do trânsito & 1 & 2 & 3 & 4 & 5 \\
\hline $\begin{array}{l}\text { Atuar em centros e postos de saúde na comunidade, hospitais, clínica psiquiátricas ou de atendimento à } \\
\text { saúde mental }\end{array}$ & 1 & 2 & 3 & 4 & 5 \\
\hline
\end{tabular}




\begin{tabular}{|c|c|c|c|c|c|}
\hline Selecionar funcionários para um novo emprego & 1 & 2 & 3 & 4 & 5 \\
\hline Identificar as representações sociais que medeiam as relações dos indivíduos com seus meios & 1 & 2 & 3 & 4 & 5 \\
\hline $\begin{array}{l}\text { Desenvolver ações para a melhoria das capacidades psíquicas individuais voltadas para otimizar o } \\
\text { rendimento de atletas de alto rendimento }\end{array}$ & 1 & 2 & 3 & 4 & 5 \\
\hline Realizar coletas de dados utilizando diferentes técnicas & 1 & 2 & 3 & 4 & 5 \\
\hline
\end{tabular}

